\title{
Election 2015: Health issues primer
}

$\mathrm{F}$ or the past 30 years, in poll after poll with only one exception, Canadians have declared that health care is the most important issue they face. Yet more than a month into the federal election campaign, health care is languishing on the list of political priorities. Why?

Health care is rarely a federal ballot question because it doesn't move voters emotionally, says Tasha Kheiriddin, a political commentator for the National Post, CBC and CTV. "The best shot to get on the agenda is to figure out which buttons to push," Kheiriddin said during an election readiness session at the Canadian Medical Association's General Council Aug. 25.

End-of-life rules, access to pharmaceutical medicine, high suicide rates: these and other highly charged issues are being put forward by advocacy groups but with little apparent effect so far.

A contributing factor may be the federal government's ongoing mantra that health care is a provincial responsibility - a skeptic might argue that this is a disingenuous response given that the feds are the fifth largest provider of health care in Canada. More pointedly, under the Canada Health Act the federal government is responsible for ensuring a system with public administration, comprehensive coverage, universality, portability and accessibility.

These were assured by the 2004 Health Accord, which stemmed from the 2002 Romanow Commission Report in response to years of declining federal funding and leadership. The Conservative government let the Health Accord expire in 2014, and with it federal financing began to decline: the provinces and territories will likely receive $\$ 36$ billion less for health over the ensuing decade. Roy Romanow, head of the 2002 commission, says the system is in distress and near its tipping point.

Underlying some advocates' calls for action are pleas for federal leadership to improve health care and, in some instances, to save it. Among the federal

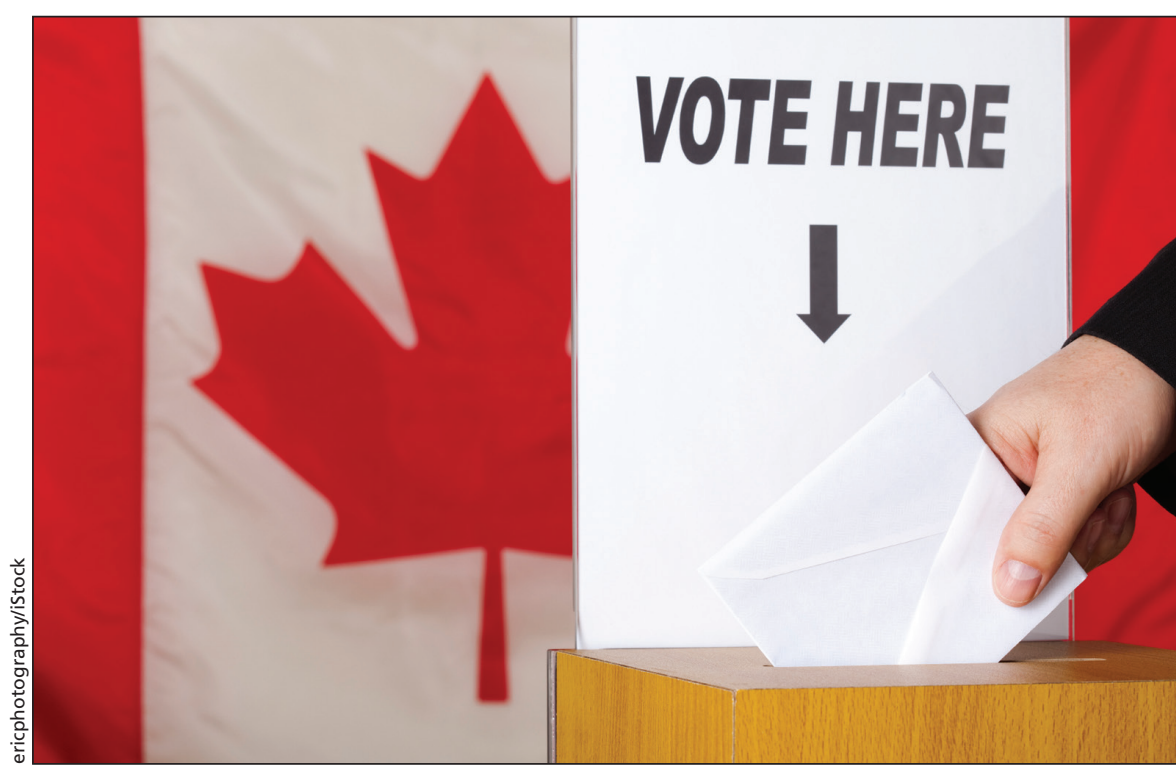

Health care is rarely a federal ballot question because it doesn't move voters emotionally, says a leading political commentator.

parties, only the Liberals have declared that health care ought to be a federal issue. In a letter to the premiers, Liberal leader Justin Trudeau wrote: "When it comes to our health and well-being, we want and expect our political leaders to make real progress on the issues that intimately affect us and our families."

What follows is a primer on some of the ongoing health care issues that the new government will have to address regardless of their stance, or lack of it, during the election.

\section{Mental health}

In a recent poll by the Mood Disorders Society of Canada, $91 \%$ of the 2245 respondents identified increasing access to mental health care professionals as a top priority. But improving services "can't be done without federal involvement as not only an initiator of increased support but also as a coordinator between the provinces and the territories," says Dave Gallson, the society's national executive director.

Mental illness constitutes more than $15 \%$ of the disease burden in Canada, but funding for mental health care is $7 \%$ of the total expenditure on health, he added.
The call for reform issued by numerous advocacy groups, including the Centre for Addiction and Mental Health, has largely been ignored by the political parties. The centre is calling for "visionary investment" from the feds that will result in improved wait times, better access for rural communities and increased access to treatment, such as cognitive behavioural therapy.

The Canadian Psychiatric Association and the Canadian Mental Health Association want a mental health innovation fund to increase the dissemination of innovative practices and improve the delivery of programs and services.

As a provider of health care, the federal government is also grappling with providing mental health care. In prisons, where $35 \%$ of inmates have two or more mental health disorders, there is a shortfall of mental health professionals. And in the military, about $20 \%$ of veterans had to wait more than eight months to receive mental health services, while about one in six full-time members of the Canadian Forces experiences symptoms of at least one mental or alcohol disorder.

In the 2015 federal budget, the government committed $\$ 193.4$ million to 
improve services to veterans and renewed the Mental Health Commission of Canada's mandate for another decade.

As of Sept. 9, the political parties have made the following commitments. Conservative leader Stephen Harper has agreed to have the commission focus on finding links between mental health issues and drugs. Both the former New Democratic Party (NDP) health critic Murray Rankin and former Liberal health critic Dr. Hedy Fry stated that if elected their parties plan on working with provincial governments on mental health care.

\section{Aboriginal health}

The grim statistics concerning the health of First Nations, Inuit and Métis people in Canada tell an unforgiving tale. These Canadians have a higher incidence of chronic illnesses (such as diabetes), illnesses that are rare in the general population (such as tuberculosis and rickets), dramatically higher levels of homicide and youth suicide, and a life expectancy five to seven years lower than non-Aboriginal Canadians.

First Nations' adults are more than twice as likely as other Canadians to die from avoidable causes (including diabetes, lung cancer, accidental injuries, drug- and alcohol-related causes and suicide), according to a benchmark Statistics Canada study published in August.

Those statistics prompted the Assembly of First Nations to launch a campaign to "close the gap." In a Sept. 2 document, the assembly called on the federal government to work with the chiefs, within two years, on a First Nations health plan that includes investments in prevention, promotion and health services, plus better access to culturally appropriate health human resources. The assembly is also asking the federal government to implement a First Nations Mental Wellness Continuum Framework, and to ensure that no First Nations' child faces delays or disruption in health services because of federal/provincial infighting over who bears the cost.

Despite the dire statistics, Aboriginal health has not taken on a prominent role in the election campaign, with the exception of promises by both the NDP and the Liberal Party to hold an inquiry into missing and murdered indigenous women, if either is elected. The Conservative Party has refused to hold such an inquiry, which is among the 94 recommendations from the Truth and Reconciliation Commission. federal government to close the gaps in health outcomes, establish healing centres, increase the number of Aboriginal health care providers and recognize the value of Aboriginal healing practices, among other health-related recommendations. The Conservative Party has promised to study the recommendations, the Liberal Party has promised to implement all of them and the NDP has pledged to work with First Nations' representatives to identify the most pressing actions required.

\section{Pharmacare}

Canadians pay some of the highest prices for prescription drugs worldwide, yet have relatively poor access to medicines. One in 10 Canadians can't afford to fill their prescriptions as compared to just one in 50 Britons, and outof-pocket costs vary widely depending on where a person works and lives. Since the 1960s, litanies of health leaders, economists and politicians have pharmacare system as a solution. Canada is currently the only country with universal health insurance that doesn't include some kind of drug coverage.
That commission also called on the urged for the creation of a national

A recent CMAJ study shows that national pharmacare could slash spending on prescription drugs by $\$ 7.3$ billion annually. Patients and the private sector would reap most of these savings. In the best-case scenario, governments stand to save $\$ 2.9$ billion; at worst, costs to governments could increase by $\$ 1$ billion, although this could be offset by long-term health gains.

The Conservatives supported universal drug coverage in 2004, but dropped the notion after taking power in 2006. They have since argued that pharmacare is a provincial responsibility. Both New Democrats and Liberals have called for a national drug plan since the last election. But currently only the Greens have included pharmacare in their platform.

\section{Assisted dying}

With the Supreme Court of Canada's unanimous decision to overturn the ban on physician-assisted death taking effect on Feb. 6, 2016, pressure is mounting for federal laws to regulate the practice. Any new rules must ensure access to medical aid in dying for competent adults who are suffering intolerably from grievous, irremediable conditions. In the absence of new laws, the burden of interpreting the court's criteria will rest on doctors, many of whom are opposed to helping patients end their lives.

Federal action has been slow to date. In February, the ruling Conservatives

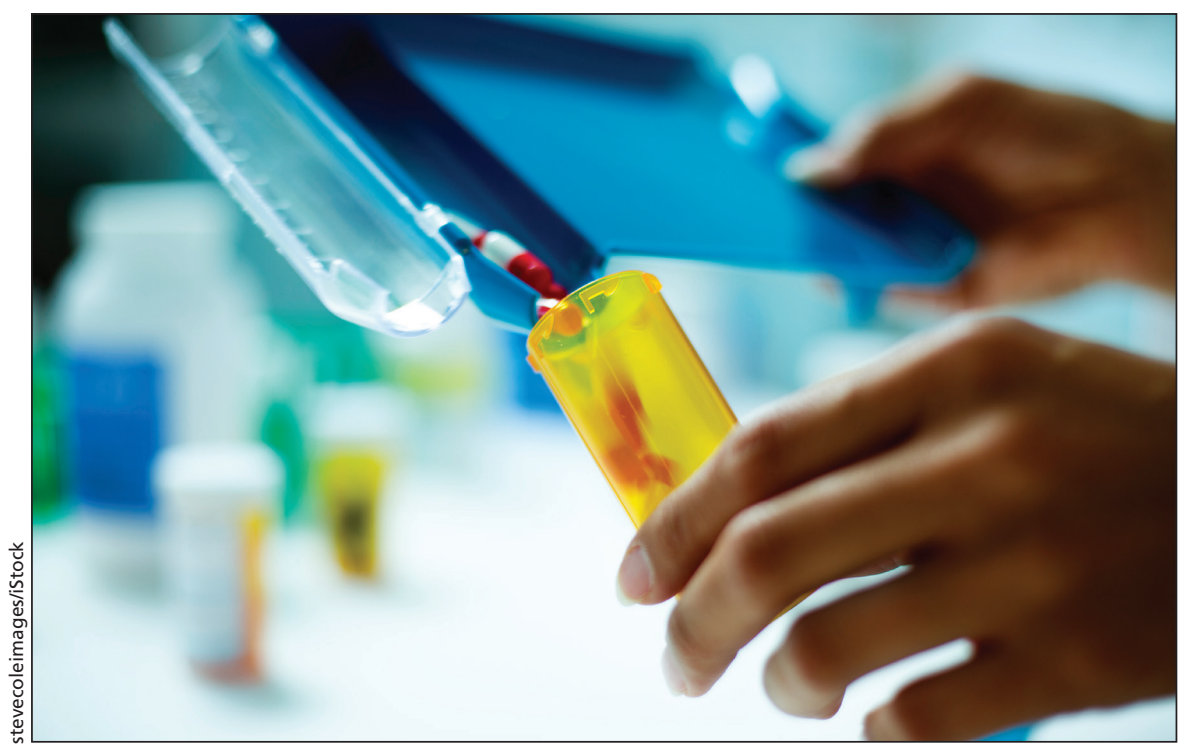

Canada is currently the only country in the world with universal health insurance that doesn't include some kind of drug coverage. 
voted down a Liberal motion to create an all-party committee to draft new laws by mid-summer. Instead, the Conservatives waited until July to appoint an expert panel, before dissolving Parliament in August. Two of the three panelists have publicly opposed assisted death, raising concern about bias.

Based on this and past votes in Parliament, experts say it's clear that a new Conservative government would introduce more restrictive regulation than other parties, or possibly abdicate the task to the provinces. The issue is less contentious among the voting public: $67 \%$ of Conservatives, $75 \%$ of Liberals, $84 \%$ of New Democrats and $88 \%$ of Greens support access to assisted death for the terminally ill.

\section{Seniors care}

By 2036, people over age 65 will make up a quarter of Canada's population (up from $14 \%$ today) and account for $62 \%$ of health costs (up from about half today). The Canadian Medical Association (CMA) is leading an alliance of 50 organizations to Demand a Plan for a national seniors strategy. Its framework calls for action in six areas, from wellness to palliative and end-of-life care.

The CMA's 2015 national report card found that $89 \%$ of Canadians agree that the winner of the upcoming election needs to address the health care needs of an aging population. So, what are the parties doing?

As of Sept. 3, CMA's "promise tracker" indicated the Conservatives had pledged five-year renewal of the Canadian Partnership against Cancer and \$50 million in new funding for seniors initiatives (starting in 2017/18). In a letter to the premiers, Liberal Leader Trudeau, pledged to focus on health care issues including coping with the aging population. The Liberals had promised to provide more flexible employment insurance benefits to Canadians caring for a seriously ill family member.
The Green Party had proposed a national seniors strategy that includes a guaranteed livable income and a nationwide pharmacare program. The NDP also touted a national seniors strategy, including boosting the guaranteed income supplement by $\$ 400$ million and reversing the decision to raise eligibility for Old Age Security from 65 to 67 . The Bloc Québécois had made no promises. - Barbara Sibbald, CMAJ

With files from Lauren Vogel, Laura Eggertson, Shannon Lough and Roger Collier.

Election news primers devoted to each of the above issues include, Election 2015: Mental health needs targeted federal funds; Election 2015: Closing the Aboriginal health gap; Election 2015: The federal flipflop on pharmacare; CMA developing assisted-death guidelines and Physicians want action on seniors care.

CMAJ 2015. DOI:10.1503/cmaj.109-5152

\section{Filling the cannabis knowledge gap}

$\mathrm{E}$ ducating physicians on medical marijuana may improve access for patients seeking an alternative therapeutic option, but it may also mitigate some of the cultural stigma that has persisted since the drug was declared illegal in 1923.

Cannabis for medical purposes was legalized in 2001 in Canada, and in 2014 Health Canada changed the rules, making licensed health care practitioners responsible for filling out the approval document - akin to a prescription - stating the dosage and the frequency of use. But in the absence of guidelines or rigorous evidence, many doctors are uncomfortable providing access to their patients.

Now educational opportunities are emerging. The College of Family Physicians of Canada (CFPC) has approved seven programs on dried cannabis; the two online ones were funded by Tilray, a licensed producer. Another cannabis producer, Tweed Marijuana Inc., launched its education program this spring. Physicians seeking an education free of industry influence can look to the
Advancing Practice online certificate program approved by the Canadian Council on Continuing Education in Pharmacy. In addition, doctors can attend seminars or dinner lectures led by researchers or fellow doctors.

Dr. David Hepburn, a family physician in Victoria, BC, is one of the latter. Over the next few weeks, he will travel to five provinces to educate other doctors on medical cannabis. "One of the leagues about the science behind cannabis and how it works in the body. Researchers only started to describe the body's endocanabinoid system in 1990 . According to Health Canada, this system appears to regulate a host of functions in the body, including neural development, appetite, pain and cardiovascular functions.

Not so long ago, Hepburn was opposed to using cannabis, but after

\section{"I began to realize the more I educated myself that - wow - we really were misled over many years."}

things I ask physicians, in a room of about 100 doctors, is 'How many of you have cannabis in your blood system right now?' You might get one or two brave souls who put a hand up, but I say the fact is you all do because you're all making your own cannabinoids."

Over the past year and a half, Hepburn has been speaking with his col- patients told him how the drug helped them, he started signing the forms to allow his patients legal access.

"I began to realize the more I educated myself that — wow — we really were misled over many years. Sometimes it's more important to unlearn than to learn."

Making education available requires funding; Hepburn fully discloses that 